\title{
The Normal Integral
}

\author{
W. J. Cody* \\ Mathematics and Computer Science Division \\ Argonne National Laboratory \\ Argonne, IL 60439-4801
}

Key Words: Normal curve.

Language

Fortran 77.

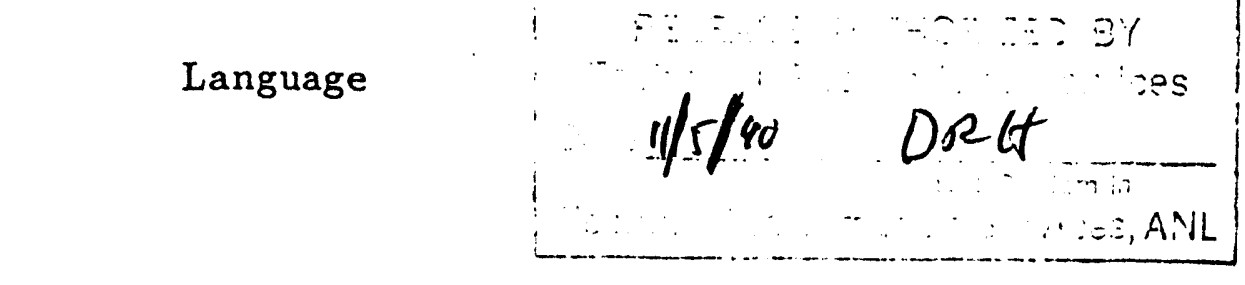

Description and Purpose

\begin{abstract}
ANORM is a reliable, portable Fortran function program, written in the style of the SPECFUN package [2,3], for computing the normal probability distribution to full machine precision on most contemporary computers. The rnain computation evaluates near-minimax approximations (derived from those in Cody [1]) that are theoretically accurate to at least 18 significant decimal digits. Special care has been taken in implementation to minimize error contamination in the crucial computation of the exponential and to provide full accuracy in the computation with large negative arguments. ANORM returns 0.0 for arguments smaller than the machine-dependent constant XLOW and returns 1.0 for arguments greater than the machine-dependent constant XUPPR.
\end{abstract}

\section{Structure}

\section{FUNCTION ANORM(ARG)}

\section{Formal parameter}

ARG Real

input: the argument value.

\section{Related Algorithms}

Algorithms AS 2 [4] and AS 66 [5] also calculate the normal integral. The advantages of our algorithm are ease of use, accuracy for the full argument range, and ease of conversion between single and double precision.

\footnotetext{
-Work supported by the Applied Mathematical Sciences subprogram of the Office of Energy Research, U. S. Department of Energy, under Contract W-31-109-Eng-38.

\section{DISCLAIMER}

The submitted manuxcript has been authored by a contractor of the U.S. Government under contract No. W.31-109ENG.38. Accordingly, the U.S. Government retains a nonaxclusive, royalty-free license to publish or reproduce the published form of this contribution, or allow others to do $\infty$. for U. S. Government purposes.

This report was prepared as an account of work sponsored by an agency of the United States Government. Neither the United Sta' is Government nor any agency thereof, nor any of their employees, makes any warranty, express or implied, or assumes any legal liability or responsibility for the accuracy, completeness, or usefulness of any information, apparatus, product, or process disclosed, or represents that its use would not infringe privately owned rights. Reference herein to any specific commercial product, process, or service by trade name, trademark, manufacturer, or otherwise does not necessarily constitute or imply its endorsement, recommendation, or favoring by the United States Government or any agency thereof. The views and opinions of authors expressed herein do not necessarily state or reflect those of the United States Government or any agency thereof. 


\section{Constants}

The constants EPS, XLOW, and XUPPR must be calculated and initialized in DATA statements. An approximate value for XLOW is the negative of the solution to the equation

$$
\frac{e^{-x^{2} / 2}}{x \sqrt{2 \pi}}\left(1-1 / x^{2}\right)=x \min ,
$$

where $x$ min is the smallest positive foating-point number. XUPPR is estimated as $\sqrt{\ln E P S}$, where EPS is the largest machine number such that $1+\mathrm{EPS}=1$. Comments in ANORM contain suggested single-precision and double-precision values of these constants for most contemporary machines.

\section{Accuracy}

The program will return function values accurate to the minimum of machine precision and 18 significant decimal digits for arguments greater than XLOW, and will return 0.0 for smaller arguments.

\section{Precision}

A single-precision version of ANORM can be prepared for a particular machine by first globally changing all occurrences of CS in columns 1 and 2 to blanks, and then specifying the machinedependent constants EPS, XLOW, and XUPPR in the DATA statements. A double-precision version can be obtained in the same manner, except that $C D$ in columns 1 and 2 must be globally changed to blanks.

\section{References}

[1] Cody, W. J. (1969) Rational Chebyshev approximations for the error function. Math. Comp. 23, 631-637.

[2] - (1987) SPECFUN - a portable special function package. In New Computing Environments: Microcomputers in Large-Scale Scientific Computing, A. Wouk, ed., SLAM, Philadelphia.

[3] - (1990) SPECFUN - a portable package of special functions and test drivers. Preprint MCSP179-0990, Mathematics and Computer Science Division, Argonne National Laboratory, Argonne, Dlinois, 1990.

[4] Cooper, B. E. (1968) Algorithm AS 2. The normal integral. Appl. Stat. 17, 186-187.

[5] Hill, I. D. (1973) Algorithm AS 66. The normal integral. Appl. Stat. 22, 424-427. 
FUNCT ION ANORM(ARG)

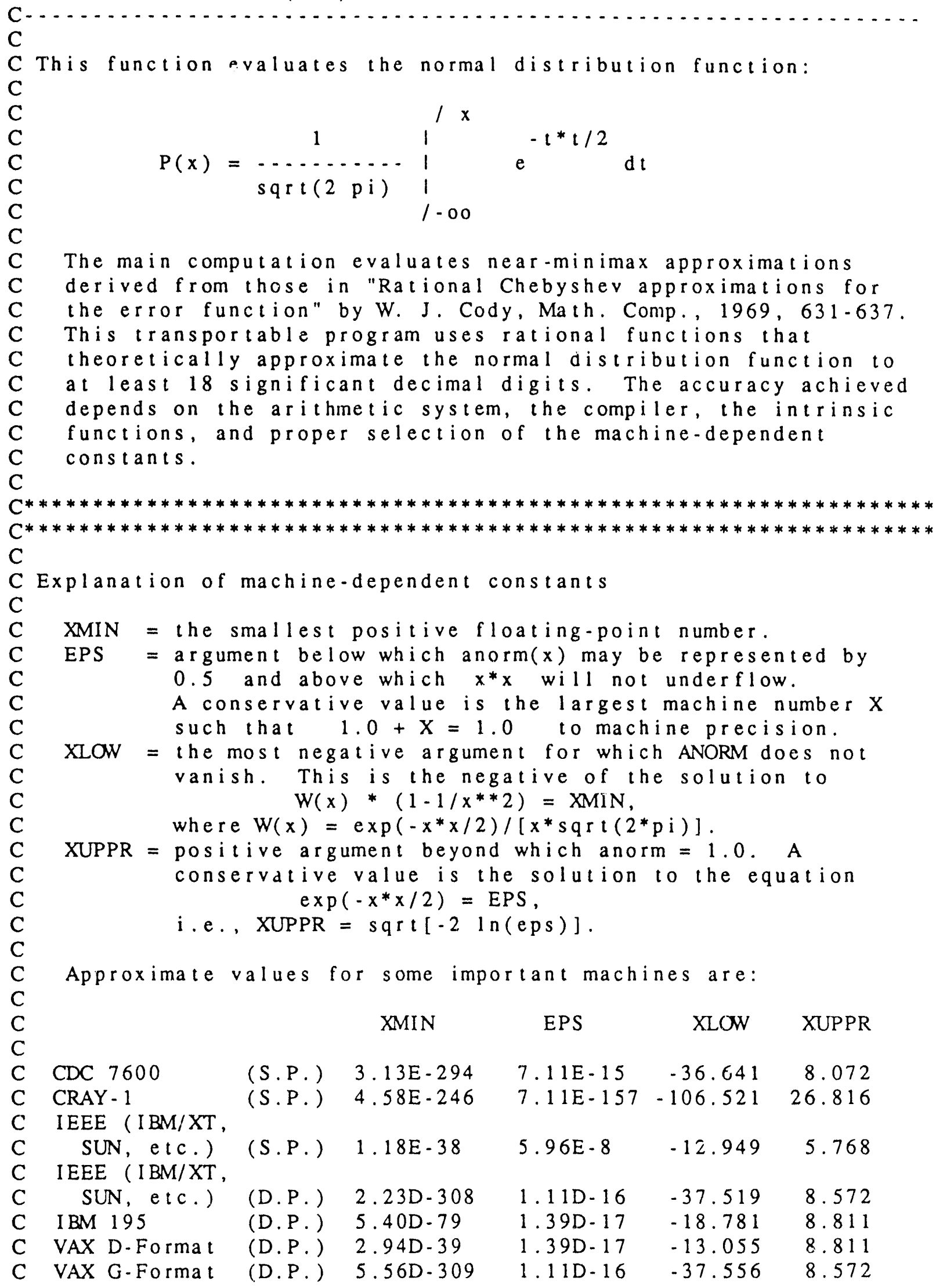




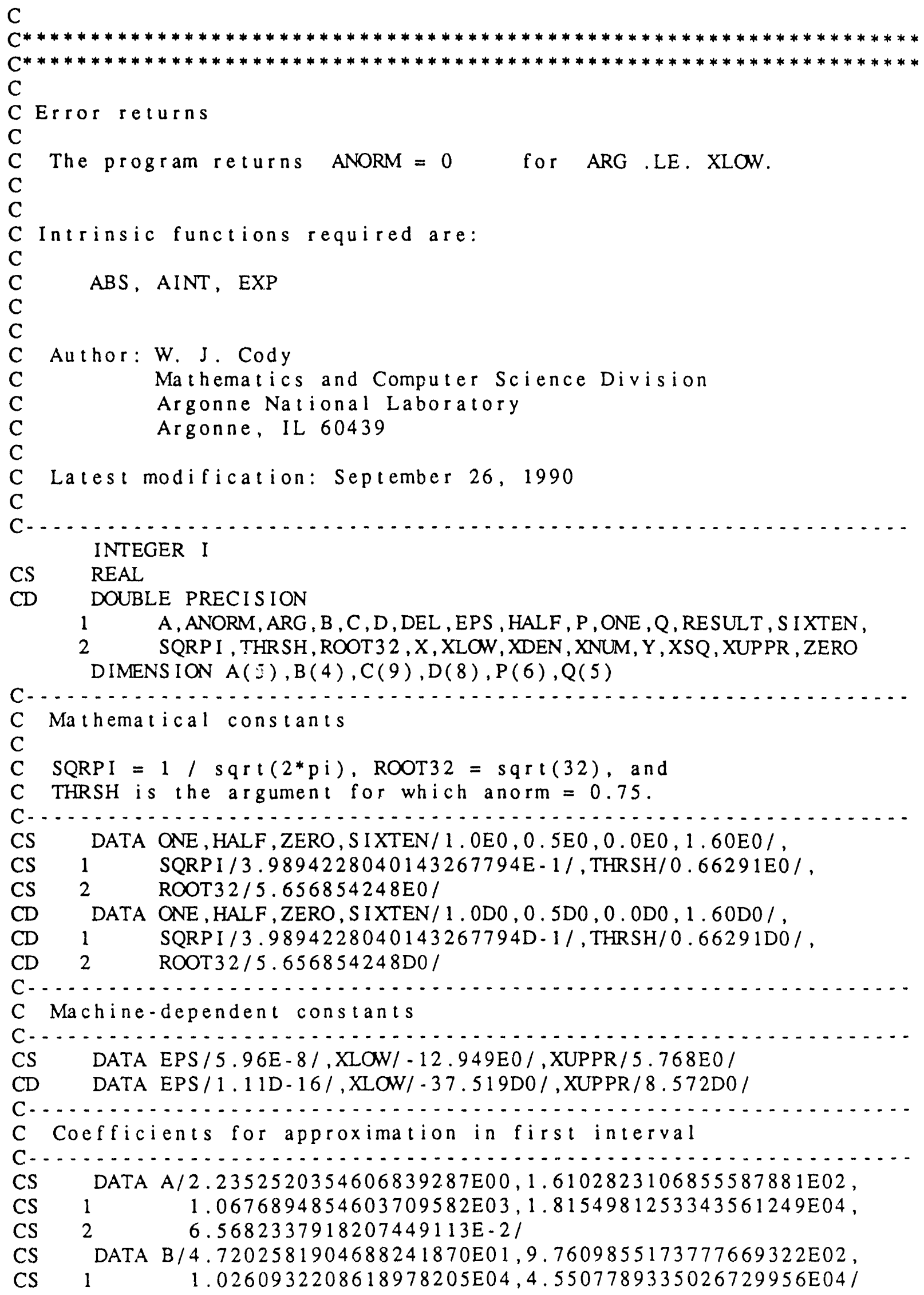




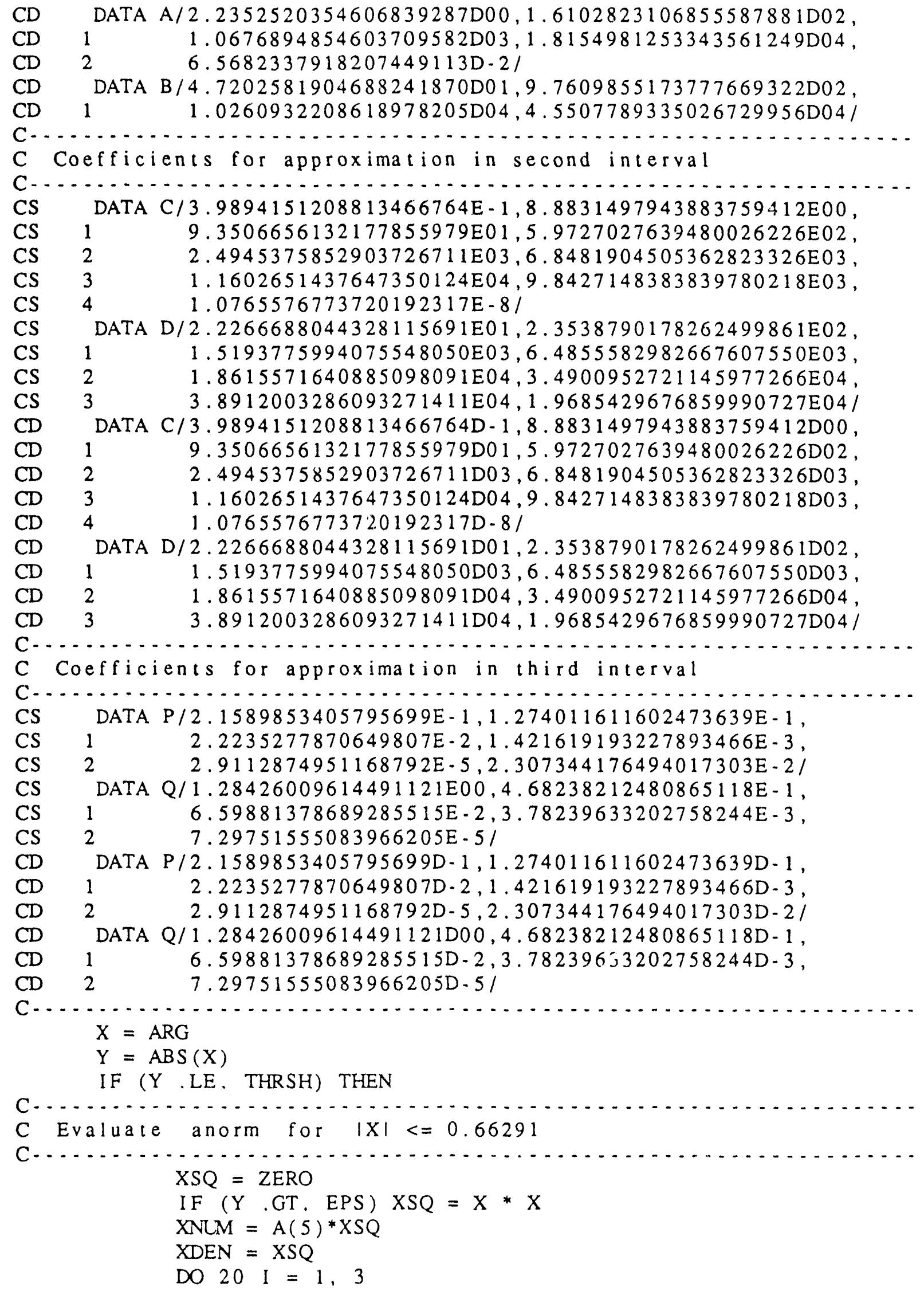




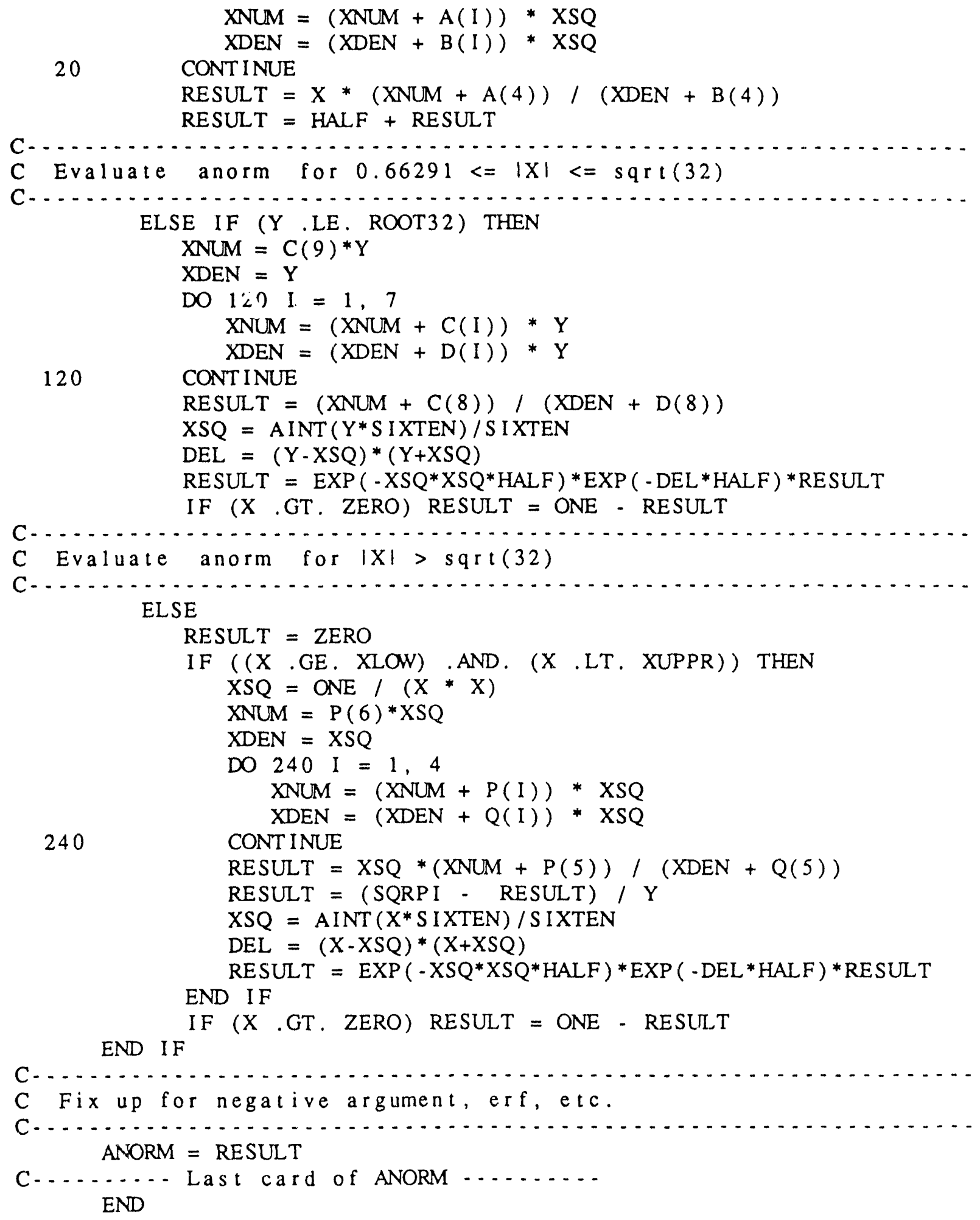



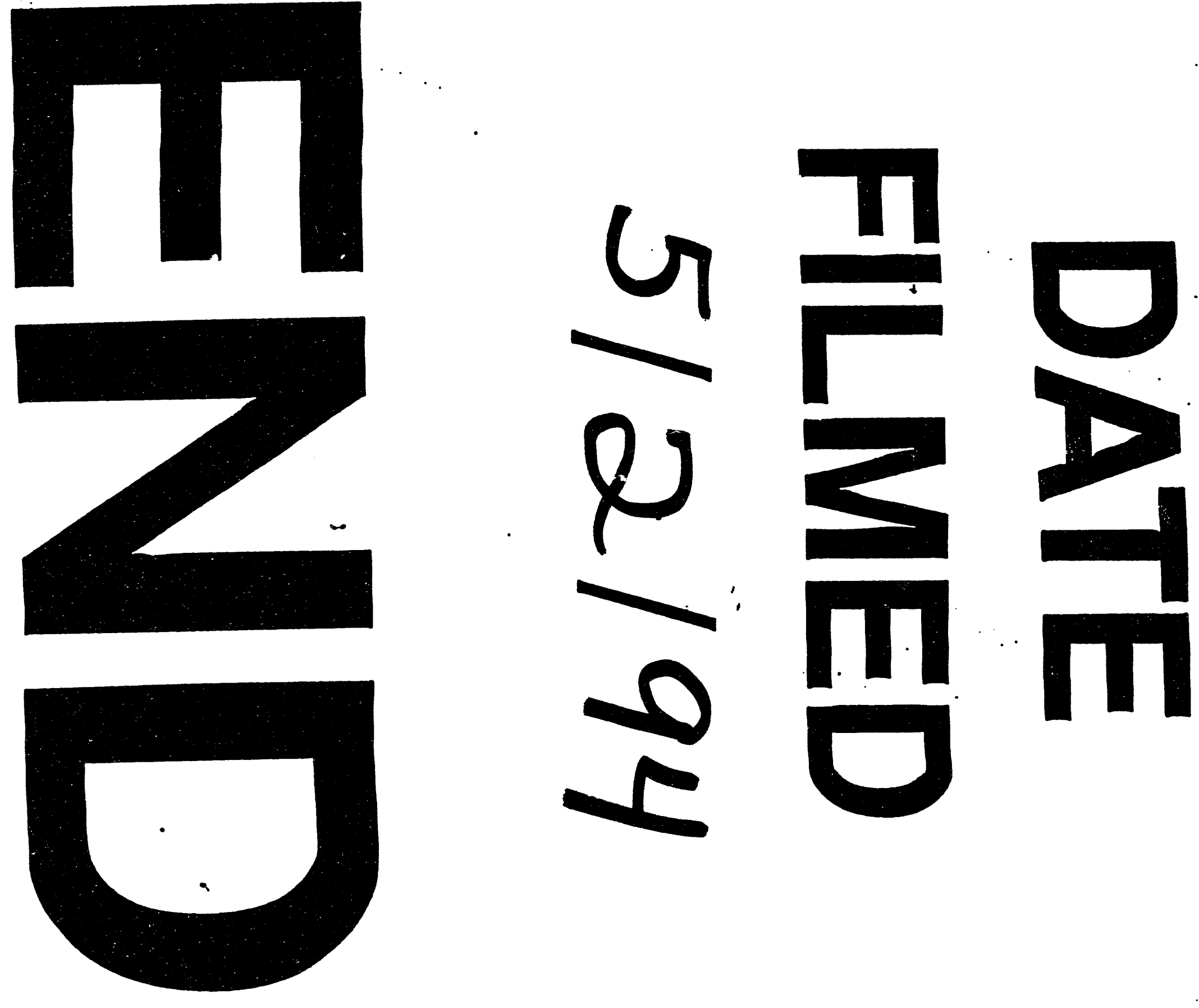
